\title{
A eugenia de ontem e de hoje
}

\section{Eugenics, yesterday and today}

\author{
Paula Arantes Botelho Briglia Habib ${ }^{i}$ \\ 'Professora, Universidade Federal Fluminense. \\ orcid.org/0000-0002-5503-5134 \\ pbrigliahabib@uol.com.br
}

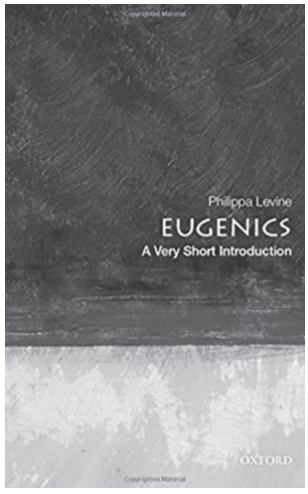

LEVINE, Philippa. Eugenics: a very short introduction. Oxford: Oxford University Press. 2017. 168p.
Eugenics: a very short introduction, de Philippa Levine, publicado pela Oxford University Press em 2017, tem dimensões modestas, mas presta um belo serviço ao tratar de assunto tão controverso e espinhoso. Os recentes estudos sobre o tema no Brasil e a constante associação entre eugenia e nazismo fazem com que o debate não seja novidade e a publicação de livros que abordem os movimentos eugênicos não seja uma surpresa. Mas, em tempos de radicalismos, intolerância de gênero, racial, social, posições políticas exacerbadas, polarizações e extremismos, a eugenia, toda a rede construída ao redor de seu movimento, seus usos, sua aplicação, suas conseqüências e suas permanências, torna-se assunto de extremo interesse e é essencial que seja sempre revisitado e discutido.

O livro faz parte da coleção "A very short introduction", publicada desde 1995; atualmente com cerca de 450 títulos, tem como proposta a apresentação dos mais variados temas, de forma "acessível e estimulante", bastante semelhante à série "O que é" publicada no Brasil pela Editora Brasiliense. Philippa Levine é professora do departamento de História da Universidade do Texas, com vasto currículo e experiência em pesquisa sobre eugenia e temas correlatos. ${ }^{1}$

Com cerca de 150 páginas, em linguagem simples e didática, o livro é dividido em cinco capítulos bem costurados entre si: "The world of eugenics"; "Eugenic intelligence"; "Eugenic reproduction"; "The inequalities of eugenics"; "Eugenics after 1945". Ao longo deles são discutidas as principais questões do movimento eugênico e suas permanências no contexto internacional, contribuindo, dessa forma, para a argumentação da autora. O livro conta com uma pequena lista de ilustrações, referências bibliográficas clássicas e atuais sobre o tema, divididas pelos cinco capítulos, e um índice bastante útil, em especial para consultas rápidas.

O livro se propõe a apresentar a eugenia como um movimento científico e social, de abrangência internacional, com influências e efeitos potentes e duradouros nas políticas 
públicas de diversos países. Para Levine, a eugenia se apresentou como a solução para os problemas causados, bem como para os problemas revelados, pela Primeira Guerra Mundial. Nesse sentido, o alcance da ciência eugênica foi longo e englobou a antropologia física, a genética, a psiquiatria, a psicologia, a criminologia, para citar alguns exemplos.

Inicialmente, a autora explica a eugenia, suas origens sociais e científicas, as principais questões que permearam o debate sobre hereditariedade desde o século XIX, mas em especial como a eugenia conquistou tantos adeptos nas primeiras décadas do século XX. Para ela, parte dessa explicação reside naquilo que chama de "paradoxo da eugenia": os princípios que motivaram os eugenistas a se engajarem no movimento, geralmente, eram bem intencionados e relacionados ao desejo de melhoramento da sociedade, ao mesmo tempo que o movimento foi associado com as principais políticas coercitivas e punitivas durante o século XX. Outra parte da explicação está relacionada à promessa de um mundo melhor, um futuro melhor, socialmente mais justo, à perspectiva da erradicação de doenças, más-formações, degenerações. Essas crenças foram capazes de seduzir uma ampla gama de cientistas, intelectuais e políticos, tanto na Europa, na Ásia, quanto nas Américas do Norte e Latina, para as fileiras dos movimentos eugênicos. Apesar de todas as promessas, Levine deixa claro que a eugenia e seus usos - políticos, econômicos, sociais e culturais reforçaram as diferenças e ampliaram as desigualdades.

Um dos principais argumentos de Eugenics: a very short introduction diz respeito ao alcance e à persistência da eugenia durante todo o século XX. Segundo Levine, uma forma de compreender o amplo espectro de influência da eugenia é observar como as ideias e pressupostos eugênicos foram absorvidos pela cultura: o tema da eugenia pode ser encontrado em filmes, livros, peças de teatro e nas artes? Sim, e uma lista de exemplos é apresentada ao leitor, mas sem o aprofundamento em questões que seriam pertinentes para uma melhor compreensão de como propostas de uma ciência e de um movimento social podem ser assimiladas de diferentes maneiras.

Levine centra sua análise no que afirma serem as duas questões básicas para o debate sobre a eugenia: inteligência e reprodução. A inteligência foi um dos quesitos mais importantes para os eugenistas e passou a ser medida pelos famosos e disseminados testes de inteligência (Intelligence Quotient, QI), a partir dos anos 1910. A autora mostra ainda quais os usos dos testes: criar estereótipos e a estrita relação entre eugenia, moral e inteligência. O estudo da reprodução foi uma das principais atividades dos eugenistas, e o casamento - o incentivo ao casamento eugênico e o impedimento do "mau" casamento -, uma cruzada eugênica. Nesse sentido, a autora afirma, ainda, que aconteceu um movimento global pela regulação e regulamentação dos matrimônios.

Ao tratar da reprodução no terceiro capítulo, Levine toca em assuntos ainda controversos nos dias atuais: educação sexual, inseminação artificial, controle de natalidade, aborto, eutanásia e esterilização. Assuntos que retornam no Capítulo 5 e ganham ares da contemporaneidade para provar a permanência das proposições eugênicas com novos contornos e, principalmente, com novos nomes no período posterior à Segunda Guerra Mundial. Aliado a isso, o desenvolvimento das pesquisas em genética humana e biologia, em biologia celular, a possibilidade do aconselhamento e rastreamento genético, a preocupação em diversos países com as altas taxas de natalidade, o desafio de alcançar 
a ideia de civilização e a busca incessante pelo melhoramento humano contribuíram para políticas de exclusão e controle populacional, por exemplo. Para Levine (2017, p.118), é correto afirmar que a eugenia não desapareceu depois da Segunda Guerra Mundial.

O livro coloca a América Latina, e o Brasil em especial, na rota dos movimentos eugênicos organizados. Entretanto, o argumento parece ser bastante generalista, entendendo-se aqui que o livro não busca uma análise da eugenia em terras tropicais. Levine associa a eugenia latino-americana diretamente ao lamarckismo e à ideia dos caracteres adquiridos, ${ }^{2}$ quando, na verdade, a historiografia tem mostrado, desde os anos 1990 - sobretudo a partir dos anos 2000 -, que os países tiveram suas peculiaridades e que contextos nacionais são imprescindíveis para a compreensão dos processos da eugenia em cada país. Em se tratando do movimento eugênico brasileiro, recentes pesquisas apontam para uma aproximação tanto da eugenia positiva quanto da eugenia negativa. ${ }^{3}$ No sentido que Levine apresenta a eugenia na América Latina, os países perdem não apenas suas particularidades sociais, culturais, políticas e econômicas, mas principalmente a possibilidade de refletir profundamente sobre questões essenciais que dizem respeito à construção da identidade nacional durante o século XX.

\section{NOTAS}

${ }^{1}$ Philippa Levine é uma das organizadoras de um importante volume sobre eugenia. Ver Levine e Bashford (2010).

${ }^{2}$ Um dos livros seminais sobre a história da eugenia na América Latina e no Brasil, The hour of eugenics: race, gender and nation in Latin America, de Nancy Stepan, publicado em 1991 e traduzido para o português em 2005, apresenta a relação entre a eugenia latino-americana e neo-lamarckismo, ao mesmo tempo que apresenta a organização desses movimentos eugênicos.

${ }^{3}$ Dois exemplos recentes de pesquisas sobre a eugenia e o movimento eugênico brasileiro que apontam para novas perspectivas de abordagem são Muñoz (2015) e Souza (2006).

\section{REFERÊNCIAS}

LEVINE, Philippa; BASHFORD, Alison.

The Oxford handbook of the history of eugenics.

Oxford: Oxford University Press. 2010.

LEVINE, Philippa. Eugenics: a very short introduction. Oxford: Oxford University Press. 2017.

MUÑOZ, Pedro Felipe Neves de.

À luz do biológico: psiquiatria, neurologia e eugenia nas relações Brasil-Alemanha (19001942). Tese (Doutorado em História das Ciências e da Saúde) - Casa de Oswaldo Cruz, Fiocruz, Rio de Janeiro. 2015.

SOUZA, Vanderlei Sebastião de.

A política biológica como projeto: a "eugenia negativa" e a construção da nacionalidade na trajetória de Renato Kehl (1917-1934).

Dissertação (Mestrado em História das Ciências e da Saúde) - Casa de Oswaldo Cruz, Fiocruz, Rio de Janeiro. 2006.

STEPAN, Nancy Leys.

A hora da eugenia: raça, gênero e nação na América Latina. Rio de Janeiro: Editora Fiocruz. 2005.

STEPAN, Nancy Leys.

The hour of eugenics: race, gender and nation in Latin America. London: Cornell University Press. 1991. 